Indexaciones: Repositorio de Revistas UCR, DIALNET, Latindex, REDALYC Directorio y recolector de recursos digitales del Ministerio de Cultura de España, Directory of Open Access Journals. Diálogos Revista Electrónica de Historia ISSN 1409-469X. Número especial 2008. Dirección web: http://historia.fcs.ucr.ac.cr/dialogos.htm

\title{
Tlatilco: retorno al elogio del cuerpo femenino
}

\author{
Mtra. Gezabel Guzmán Ramírez
}

Nevado de Toluca No. 5 Col. Lomas de Occipaco, cp. 53247

Naucalpan, Estado de México $01(52) 5553736207$

gezabelguzman@gmail.com

Profesora investigadora de tiempo completo de la Universidad Autónoma de la Ciudad de México 


\section{Tlatilco: retorno al elogio del cuerpo femenino ${ }^{1}$}

\section{Introducción}

El presente trabajo se encuentra dividió en cuatro partes, primero acompañado de un número circular, un preludio, en el cual doy un pequeño panorama histórico y cultural en torno a Tlatilco, deteniéndome ante dos preguntas: ¿qué guardaba Tlatilco en sus entrañas para mantenerlo oculto o resguardado?, y, ¿qué significado guarda el ser nombrado el centro de la tierra? A continuación, la parte de la matriz y el ombligo, donde el glifo redondo de Tlatilco me ayuda a reflexionar en su continuidad y su función como cementerio-templo donde las figurillas femeninas se hacían presenten en rituales funerarios acompañando cuerpos en su transición de vida y muerte. Posteriormente, dentro de un elogio al cuerpo femenino rescato una muy pequeña parte de la gran cantidad de figuras femeninas plasmadas en barro por la cultura Tlatilca, es una muy bella escusa para hablar de la danza, de la desnudez, de la ternura y la belleza del cuerpo femenino. Y finalmente, bajo el recurrente elogio del cuerpo femenino, me detengo con un modesto acercamiento a una figurilla femenina llamada "mujer embarazada", la cual, me permite entrelazar el preludio, la matriz y el ombligo con el elogio al cuerpo femenino.

Tlatilco posee ocho siglos de historia de Mesoamérica, los cuales en gran medida siguen depositados en tumbas sin descifrar. Ante los descubrimientos de varios enterramientos en la década de 1950, lo que se hacía generalmente era tomar notas detalladas de los hallazgos sin profundizar en sus simbolismos, por lo cual, este es un trabajo que lleva consigo la intención de rescatar el simbolismo de la cultura tlatilca.

1 Trabajo realizado a lo largo del Seminario de investigación Femenino Masculino: Fuentes antropológicas, hermenéuticas e históricas, del Programa Universitario de Estudios de Género (PUEG) de la Universidad Nacional Autónoma de México (UNAM). 
Dejo en el tintero las reflexiones en torno a si las figurillas femeninas portan máscaras o no, quién las fabricaba, quiénes eran enterrados/as, el papel del hombre y la mujer en la sociedad tlatilca, la búsqueda de una posible sociedad matrilineal, el culto a una o varias diosas, el significado de la mutilación dentaria y la "deformación" del cuerpo. Dejo para la reflexión de otros trabajos ocho siglos de cultura tlatilca en la Cuenca de México y me quedo con la unión de su glifo y la fecundidad femenina como ejemplos de continuidad y de retorno.

\section{Cero: preludio}

Cada uno de los instantes de nuestra vida se va a repetir infinitas veces, por lo que, estamos clavados a la eternidad. Con el tiempo a desaparecido de Tlatilco la jicotea, el zacatuche y el tecolote cornudo ${ }^{2}$ para después bajo el crepúsculo de la desaparición perder incluso el nombre de Tlatilco y llamar a la Cuenca: San Bartolo; nombre que al ser pronunciado lo baña todo con la magia de la añoranza.

Respecto a la repetición, a veces, cuando llueve, una tortuga de charco -como las que había en Tlatilco- se aparece en mi jardín. Yo la he visto en diferentes momentos a lo largo de mi vida, sobre todo cuando ya había olvidado que existía. Sin duda, en el mundo del eterno retorno como dijo Kundera ${ }^{3}$ descansa sobre cada gesto el peso de la insoportable responsabilidad. El compromiso de contar lo visto para evitar la circunstancia atenuante de la fugacidad. La deuda con el pasado-presente-futuro, con el retorno donde alguna vez haya de repetirse todo tal como lo hemos vivido.

Tal vez por eso, para evitar la fugacidad de lo vivido he de contar que sobre las tumbas de Tlatilco

2 Roberto García, Carmen María Pijoan y Marcela Salas, San Luis Tlatilco, México. Catálogo de entierros. Temporada IV. (México: Instituto Nacional de Antropología e Historia, 1991), 14.

3 Milan Kundera, La insoportable levedad del ser. (F, Valenzuela, Trad.) (México: Tusquets, 1985), 3. 
yo aprendí a caminar. Éstas me quedaban a varios pies de profundidad pero bajo mis pisadas tal vez estaban ocultos más enterramientos que los 213 o 340 descubiertos ${ }^{4}$

-el número cambia según el/la autor/a-. También he visto como a los huidizos ríos de los Cuartos, Hondo y Totolica los han cambiado con el tiempo hasta dormir ahora bajo la tierra como cuerpos enterrados, sumergidos bajo piedras, contenidos, entubados.

Pero juguemos a las remembranzas. En el pasado, Tlatilco ${ }^{5}$ - hoy Naucalpan Estado de México- se comunicaba con los lagos de Xaltocan, Zumpango y Texcoco, de agua salada y con los lagos de Chalco y Xochimilco, de agua dulce ${ }^{6}$.

Tal vez, -bajo esos lúdicos recuerdos que ahora plasmo- yo fui en esa época solo un miembro más del grupo nómada que incursionó en la vida sedentaria. Quizá contemplé el crecimiento demográfico de la aldea, la producción masiva de cerámica, el intercambio de materias primas con otras regiones, la construcción de terrazas, presas y canales para el control de agua ${ }^{7}$. Es decir, contemplé y contemplo la existencia del retorno, la transformación de mi escenario en otro; veo los cambios del paisaje a escenarios urbanos pero aún ahora la producción de cerámica -en dimensiones diferentes y bajo otro simbolismo- se mantiene, se sigue controlando el agua, el comercio con otras regiones no desapareció y hay letreros con el nombre de Tlatilco en diferentes

4 Roberto García, San Luis Tlatilco, México. Catálogo de entierros. Temporada IV, (México: Tusquets, 2007), 22.

5 La sedentarización y el crecimiento demográfico establecieron las bases para el desarrollo de las sociedades que en los siglos siguientes hicieron de la Cuenca de valle de México una de las más influyentes del México antiguo y es ahí donde Tlatilco se ubica, en el período Preclásico Medio -1200 - 400 a.C.- también conocido como período Formativo. García, "San Luis Tlatilco, México. Catálogo de entierros. Temporada IV", 19.

6 Roberto García, "La Cuenca de México. Preclásico temprano y medio (2500 - 400 a.C.) Las primeras sociedades agrícolas", Arqueología mexicana. (México) XV, n 86 (2007): 29

7 García, "La Cuenca de México. Preclásico temprano y medio (2500 - 400 a.C.) Las primeras sociedades agrícolas", 28 y Patricia Ochoa, "Cuerpos en fiesta. Las mujeres bonitas del México antiguo", México en el Tiempo. (México) 7 (junio-julio 1995): 3. 
partes. Actualmente, además de poder leer señalamientos para calles y lugares, bajo ese nombre, en el museo del sitio se puede leer:

"Tlatilco en nahuatl de tlalxicco de tlalli que significa Tierra, yxctli que significa ombligo o centro y co sufijo de lugar, es decir, El centro de la Tierra". Así, del nombre del lugar destinado como cementerio-templo, también se deriva de la palabra tlatia que significa guardar, esconder o quemar y co: lugar, es decir, Lugar de las cosas ocultas ${ }^{8}$. Pero, ¿qué guardaba Tlatilco en sus entrañas para mantenerlo oculto o resguardado? y ¿qué significado guarda el ser nombrado el centro de la tierra?

\section{Uno: la matriz y el ombligo}

La idea del eterno retorno es misteriosa porque la eternidad así lo es. Si acaso hay que dibujar a la eternidad a ésta se le puede situar la imagen del círculo. Imagen sin dirección que no puede verse como comienzo y fin, que representa la perfección, la infinitud y lo absoluto ${ }^{9}$.

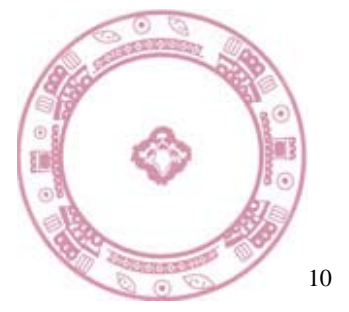

La imagen mostrada en líneas anteriores es el glifo de Tlatilco, el cual está constituido por un círculo contenido en otro. En su centro se inmoviliza una forma que recuerda a un espejo de pirita, utensilio empleado también en algunas estatuillas femeninas típicas de la producción de 8 Blanca Solares, "La cara femenina de Dios. Aproximaciones al fondo matricial mesoamericano", en Los lenguajes del símbolo. Investigaciones de hermenéutica simbólica, ed. Blanca Solares (España: Anthropos. CRIM, 2001): 251. y Francisca Martín-Cano, "Prehistoria de Suramérica: manifestaciones artísticas", (2001) http:// es.geocities.com/culturaarcaica/preh.suramerica.html (Fecha de acceso: 18 de septiembre del 2007)

9 Gezabel Guzmán, Pensamiento mítico social: construcciones en torno al mal (México: Tesis de Maestría Universidad de las Américas, 2005), 145.

10 "Tlatilco" www.naucalpan.gob.mx (Fecha de acceso: 17 de noviembre del 2007) 
cerámica de este sitio -ver imagen 1 del anexo-.

Dentro de su circunferencia se encuentran imágenes que pueden representan corrientes de agua, movimientos de serpientes, semillas, granos, hojas, flores, pero sobre todo se encuentran otros círculos contendidos a su vez entre otros. El glifo encarna la repetición, la continuidad y la protección. Ya que el círculo también es una imagen que guarda un centro sagrado, es decir, es un límite de resguardo.

Tlatilco estaba familiarizado con la naturaleza y sus ciclos vitales de día y noche, de nacimiento y muerte. De esta forma, la tierra podía ser considerada como aquella fuente vital que da frutos y que da vida, como la capacidad femenina de engendrar. De igual manera, estas escenas de agua, ríos, animales y fertilidad, se ven reflejadas en la producción de cerámica como un intento de perpetuar la continuidad, lo cual, forma parte de una cosmovisión tlatilca del mundo y del universo.

El círculo es una figura dinámica que representa el crecimiento natural, el movimiento de las estrellas, la forma de la tierra, la reunión junto al fuego, la danza ${ }^{11}$. Es por tanto, la energía de la madre tierra que puede ser recreada en rituales de fertilidad. También representa el ciclo de la vida y el renacimiento, donde se ubica el nacimiento y la muerte ${ }^{12}$.

Tlatilco como cementerio-templo nombrado el centro de la tierra o el lugar de las cosas ocultas, utilizaba esta circular imagen para representarse a sí mismo. Por un lado, el círculo encarna un límite prohibido entre el adentro y el afuera, encontrando su región dentro de un mundo dividido en una dualidad: la vida y la muerte. El círculo es un símbolo que en algunas culturas se encuentra asociado con la fecundidad y se utiliza en festivales y carnavales; su

11 Hans Biedermann, Diccionario de símbolos. (J. Gordo, Trad.) (México: Paidós. 1993), 80.

12 Sandra Forty, Symbols. (San Diego California, Estados Unidos: Thunder Bay, 2003), 190. 
significado como menciona Forty ${ }^{13}$, proviene del concepto de resurrección de plantas y animales las cuales después de estar "muertas" vuelven a la vida, aludiendo así a la continuidad. Por tanto, el círculo es la energía de la madre tierra que puede ser recreada en rituales como los de fecundidad o abundancia donde se representa el ciclo de la vida.

El mundo de naturaleza redonda, la luna circular y los océanos contenidos dentro de una esfera posibilitan hoy en día representar en el círculo el símbolo de la tierra ${ }^{14}$. Tierra que a su vez puede representarse en objetos naturales como piedras, como la pirita en el glifo de Tlatilco, la cual funciona como un espejo que permite mirarse a uno mismo, mirarse desde el centro y a partir de la continuidad de la vida.

$\mathrm{Al}$ saber que la forma circular tiene un fuerte simbolismo espiritual se entiende que Tlatilco como lugar de cosas ocultas, guardaba artificios sagrados, contenía piezas místicas y cuerpos enigmáticos con un cargado simbolismo de la dualidad. Tema que surge en Tlatilco y cuyo origen probable se encuentra en el concepto de vida y muerte, el cual fue plasmado en el dimorfismo sexual o en figuras con dos cabezas o una cara con tres ojos -ver imagen 2 y 3 del anexo-.

Esta región nombrada el centro de la tierra era como una gran matriz desde donde surge la vida, el retorno, el nacimiento y la muerte o como un ombligo donde en él estaba el núcleo de la vida, la conexión con el más allá, con la fuente que alimenta, idea que también se repite en algunas estatuillas femeninas.

Tlatilco como centro se tornaba muy posiblemente como un lugar sagrado de encuentro, de conmemoración y de continuidad. Plasmaba en su cerámica toda una cosmovisión del mundo, por ejemplo, a manera de pronunciarse desde los extremos o desde las orillas de un centro, se 13 Forty, 218.

14 Forty, 91. 
pueden encontrar imágenes detalladamente esculpidas como la embocadura de una vasija, los labios elipsoides marcados alrededor de la boca puestos en figurillas femeninas o en animales, los contornos circulares que enmarcan la profundidad de los ojos de estas figuras; serpientes que atisban dentro de una circular vasija donde se resguarda algo sagrado o serpientes que contienen en sus bocas esferas -ver imagen 4 y 5 del anexo-.

En las tumbas, los habitantes de Tlatilco colocaron también cerámica ritual y utilitaria, sellos para imprimir diseños geométricos sobre el cuerpo. Estos diseños decoraban todos los implementos de la cultura material de la aldea, repitiéndose en las figurillas y las vasijas. Se trata de un lenguaje de signos codificados, en el que la V, la M, el zigzag, la greca y el espiral se repiten sin cesar, aludiendo a corrientes acuáticas, serpientes y a ideas de fecundación, multiplicación y continuidad. También aparecen imágenes de hechiceros con máscaras, el concepto dual de vida y muerte y los fenómenos naturales expresados en forma abstracta ${ }^{15}$.

Pero dentro de este mar de cerámica sobresalen la gran cantidad de figurillas femeninas depositadas como ofrendas mortuorias. Estas piezas, realizadas mediante el modelado manual del barro y pintadas con exquisito cuidado demuestran "una entrega a los momentos festivos, eróticos y lúdicos en un auténtico culto a la desnudez decorada del cuerpo, cadenciosamente modelada por la música y la danza"16.

Así, las tradiciones tlatilcas se impregnaron de magia y fueron inmortalizadas en las figurillas femeninas que simbolizaban en parte, el culto a la fertilidad. Así, en el ombligo de este universo o el centro de la tierra lleno de cosas ocultas, el foco principal lo ocupaban las desnudas -o poco

15 Martín-Cano, 8. y Román Piña, Tlatilco a través de su cerámica. (México: Talleres de Edimex, 1958), 20.

16 Solares, 253. 
vestidas- estatuillas femeninas adornadas de pintura corporal. Las cuales llevan en sus cuerpos una cargada simbolización del pensamiento tlatilca.

\section{Dos: elogio al cuerpo femenino}

Los cadáveres encontrados en asentamientos de Tlatilco, no presentan una marcada diferencia en la estructura del esqueleto. Como lo menciona García ${ }^{17}$, en ambos sexos los huesos en general son masivos y con fuertes inserciones musculares, rasgos relacionados con la actividad que efectuaban tanto hombres como mujeres. Es decir, parece ser que estos cuerpos hablan de actividades de trabajo no tajantemente diferenciadas por sexo. Por otro lado, la mortalidad de la población era de alrededor de 35 años en ambos sexos, con una esperanza de vida de 26 años, y con una elevada tasa de mortalidad infantil, sin que esto signifique que no había gente que sobrepasaba este rango de edad. Desde este punto, la representación grafica en cerámica de la vida cotidiana también muestra cuerpos en ciclos de vida determinados. Es decir, figurillas femeninas jóvenes, engalanadas de pintura corporal, pulseras, orejeras, collares, pectorales y lazos. Vistiendo a veces una pequeña faldilla, siempre con estilizados peinados trenzados, con listones e incluso con turbantes. Como lo menciona Paul Westheim ${ }^{18}$, "creo que podemos dar por seguro que estas figurillas nacieron de la alegría de crear y del deleite de la belleza del cuerpo femenino".

-ver imagen 6 en el anexo-

En estas mujeres bonitas, como se les conoce, se dramatizan sus rasgos femeninos como las anchas caderas, la estrechez de la cintura o los senos, piernas bulbosas o de cebollas y facciones 17 García, "La Cuenca de México. Preclásico temprano y medio (2500 - 400 a.C.) Las primeras sociedades agrícolas", 29.

18 Citado en Solares, 254. 
muy finas. Con rostros infantiles, cuerpos adolescentes con cabellos rojos. En las figurillas se esquematizan otras partes del cuerpo considerados de menor importancia de acuerdo al mensaje que desea transmitirse, como los brazos o las piernas, que se convierten en muñones. Es importante señalar que estas piezas fueron encontradas en tumbas, por lo cual, sus posiciones naturales eran acostadas, así, los pies que sostienen el cuerpo en pie pueden ser omitidos.

Las piezas femeninas generalmente se encuentran desnudas, algunas traen faldillas o pantalones de cascabeles posiblemente representando semillas o granos, pero siempre con el torso al descubierto. Si acaso se encuentran piezas con brazos o manos, estos se tocan el cuerpo en sus zonas eróticas o sexuales -ver imagen 7 en el anexo-.

Todos los rasgos de feminidad como los senos, las caderas, los vientres prominentes, el líquido menstrual, se asocian a una serie de poderes fertilizadores que las mujeres comparten con la tierra. El corpus de figurillas de Tlatilco es mayormente una exaltación de esta feminidad fértil, sexual y dadora de existencia, que comparte sus ciclos de vida con los ciclos de la naturaleza. La veneración a la tierra como madre, habría derivado en una veneración a la mujer y a lo femenino por equiparación. De tal modo, se pueden encontrar figurillas que representan condiciones de la feminidad como mujeres en parto, amamantando, con cuerpos que han parido, embarazadas o de jóvenes mujeres que se inician en este paso de dar vida. Estas figurillas se suelen encontrar rodeadas de otras mujeres o solitarias, llorando o riendo, con criaturas o infantes y en algunos casos en contacto estrecho con animales -ver imagen 8 en el anexo-

Cabe mencionar que estas pretty ladies no son necesariamente mujeres reales sino imágenes de la feminidad. Están adornadas como lo menciona Ochoa ${ }^{19}$, con aparentes tatuajes o pintura 19 Ochoa, 5. 
facial y corporal, tienen el rostro y el cuerpo decorado con bandas y líneas de colores blanco, amarillo, rojo y negro. Las estatuillas eran pintadas con los muslos llenos de diseños geométricos, círculos concéntricos y zonas cuadriculadas; también tenían la costumbre de pintar todo un lado del cuerpo, dejando el otro sin decoración, a manera de contraste simbólico.

Los cadáveres encontrados en las tumbas estaban rociados de cinabrio, por lo que, algunas figurillas que acompañaban estos cuerpos también mostraban ese color rojo. Aunque pueden verse figurillas pintadas de manera planeada en colores amarillos, morados, rojos y blancos. Son cuerpos que dan una imagen tierna de maíz virginal. Granos de maíz que iluminan los cuerpos. Figurillas asemejadas al maíz fruto sagrado que permite la vida.

Estos cuerpos de figurillas en fiesta muestran el movimiento que se plasma de la forma más libre en las bailarinas, que representan la gracia, la belleza y la delicadeza de lo femenino. Mezclado con el poder de dar vida ${ }^{20}$.

\section{Tres reflexiones finales: recurrente elogio del cuerpo femenino}

Frente a estas figurillas deseo detener la fugacidad del tiempo un momento. Haré alusión al retorno en el cuerpo, en el cual se ofrece a la mirada con su propia mirada abarcadora del mundo y de la vida, sin duda como menciona Huerta ${ }^{21}$ vemos estos objetos de cerámica y ellos nos miran a su vez, en un diálogo hecho de pura luz intermediaria, cuyos puntos de origen son principalmente la arcilla y la piedra. Material que sirve de excusa para el simbolismo en el cuerpo; sin duda estas figurillas femeninas son un acto de provocación a nuestros sentidos y sensibilidad.

Pero me detengo a analizar una figura particular. Durante todo el período preclásico fue común asociar la representación de mujeres embarazadas a la agricultura y la abundancia. Y Tlatilco 20 Ochoa, 5.

21 David Huerta, "Cosmos de flor y canto. Los cuerpo y los siglos", Elogio del cuerpo mesoamericano. Artes de México (México) 69 (2004): 44. 
cuenta entre su variedad de figuras con "mujer embarazada", pieza que se conjetura fue usada como amuleto de fecundidad -ver imagen 9 en el anexo-.

Esta pieza coloca al cuerpo como frontera sagrada y nos permiten tocar con otros ojos nuestros cuerpos más antiguos. Es la imagen del proceso de la vida puesto en un cuerpo femenino. Como menciona Arroyo ${ }^{22}$, en el territorio del cuerpo se han trazado los caminos del lenguaje, la corporalidad ha definido a los grupos humanos y ha sido el lugar privilegiado para expresar la imagen del mundo de cada civilización. Y sin duda en Taltilco, bajo su concepción agrícola de opuestos complementarios, la estación de las aguas impulsó la unión simbólica de la mujer, la preñez, la germinación, la humedad, la oscuridad, la riqueza, el inframundo y la muerte, esta última como generadora de vida ${ }^{23}$.

De este modo, Tlatilco como centro y cementerio-templo era el sitio donde se transitaba de la vida hacia la muerte y de la muerte hacia la vida, un amuleto de mujer embarazada puesto en una tumba podría asegurar posiblemente un nuevo nacimiento. Tlatilco como centro y ombligo plasmaba en sus figuras la cicatriz que queda tras el rompimiento del cordón umbilical, esa vía de alimentación que sujeta la existencia de la no existencia. Una vez que el cordón umbilical resultante después del parto, se cae entre una a dos semanas después del nacimiento, se forma el ombligo del nuevo ser. En consecuencia, la figura de "mujer embarazada", lleva consigo la posibilidad de la vida, la conformación de un nuevo individuo, representa la abundancia, el alimento, la transición en el cuerpo.

Finalmente, Tlatilco como matriz o útero otorga la posibilidad de guardar lo oculto, lo desconocido,

22 Sergio Arroyo, "Cosmos de arcilla y piedra. Elogio del cuerpo", Elogio del cuerpo mesoamericano. Artes de México (México) 69 (2004): 8.

23 Alfredo López, "Cosmos vivo. La concepción del cuerpo en Mesoamérica", Elogio del cuerpo mesoamericano. Artes de México (México) 69 (2004): 20. 
lo sagrado. Por lo tanto, el cuerpo femenino por su capacidad de depositar y engendrar el misterio de la vida se asemeja a la naturaleza considerada también sagrada, sin perder de vista, que el útero hace alusión al inframundo, a la muerte y en oposición al retorno.

Muchas sociedades de tipo agrícola que poblaron la tierra en distintos lugares y en distintos momentos, profesaron una serie de creencias estrechamente ligadas a la fertilidad de la tierra y a lo femenino. El concepto de Madre Tierra, como dadora de vida y muerte, otorgadora de habilidades y perpetuadora de la especie es una idea universal que observa y convive con los ciclos de la naturaleza y los asocia a la fertilidad de la mujer. De esta forma, encontramos en el arte antiguo representaciones antropomorfas de mujeres, más o menos esquematizadas, que resaltan los rasgos que se identifican con la feminidad, ligada a la fertilidad como "mujer embarazada" en Tlatilco.

Se encuentran figurillas que representan mujeres en registros arqueológicos de la Europa neolítica, de las primeras civilizaciones asiáticas y de los pueblos primitivos africanos. Todas estas piezas, están realizadas en estilos muy distintos entre sí, pero siempre parecen compartir una premisa: el dar importancia dentro de la representación a los rasgos que subrayan la feminidad. Incluso a veces los signos y los objetos que acompañan a las estatuillas femeninas de los distintos pueblos agrícolas presentan semejanzas verdaderamente impresionantes, teniendo en cuenta que el contacto entre ellos suele ser un hecho imposible. Existe todo un lenguaje inherente a este tipo de sociedades, como signos en forma de espiral, de V, de zigzag y otra serie de motivos geométricos que aparecen indistintamente en América, Asia, África o Europa ${ }^{24}$. Por ejemplo, en un megalito que se encuentra en el interior de un templo de Tarxien, Malta, que data del 3000 a.C, su decoración en espirales dobles es exactamente la misma que el sello para imprimir pintura 24 Martin-Cano, 10. 
procedente de Tlatilco, México, año 1200 a.C. Este sello formaba parte de la ofrenda mortuoria de una joven mujer, que fue enterrada con un número importante de figurillas femeninas. La espiral se relaciona con la fertilidad, la feminidad, las corrientes acuáticas y la serpiente, ya que simboliza el crecimiento y el cambio constante inherentes a la naturaleza. Algunas figurillas femeninas fueron encontradas acompañando a los/as difuntos/as y representaban la Gran Diosa Madre, por lo cual, eran rotas ritualmente, seguramente para dejar salir del interior del vientre de la Diosa los cimientos de la procreación, como semillas de vida ${ }^{25}$.

Pero como menciona Raúl Flores ${ }^{26}$, nunca más en el arte prehispánico volverá a repetirse tal aliento de humanidad como en Tlatilco, ya que en las figuras de este período cada momento maternal, matricial y maduro, de la mujer invadida del misterio milagroso de generar la vida a través del cuerpo, se encuentra representado en mujeres embarazadas, con senos y vientres rebosantes, casi siempre palpando éste último con una mano y auscultándose a sí mismas. En ciertas figuras algunas veces su rostro ríe satisfecho, otras se levantan hacia el cielo. Se plasman en arcilla mujeres en pleno dolores del parto, tendidas en un camastro, asistidas por una comadrona o en el fondo de una vasija, rodeadas por un coro de otras figurillas femeninas que atisban desde los bordes. Mujeres pariendo acostadas o en cuclillas, otras sujetando a su bebé con vida, replicando el rostro de la madre y chillando al unísono de ella. Finalmente, madres que amamantan a sus hijos/as y que los/as mecen en cunas de mimbre, alzándolos/as en sus brazos y que juegan con ellos/as dejándolos/as subir sobre sus hombros ${ }^{27}$, imágenes por demás recurrente en nuestros días.

25 Martin-Cano, 10.

26 Raúl Flores, Historia general del arte mexicano. (México: Hermes, 1968), 59.

27 Solares, 255. 
Algo muy interesante que la cultura tlatilca no olvido plasmar en su cerámica y en especial en las figurillas femeninas fue la continuidad. Que mejor imagen para la eternidad que los círculos como cuevas, profunda y cuidadosamente puestos en el cuerpo. "Mujer embarazada" nos permite ver en el lenguaje de su cuerpo a la continuidad circular encarnada. Unos labios y ojos elipsoides que albergan un profundo orificio central, las orejas como pequeñas cuencas circulares perfectamente delineadas con su centro hueco esperando a ser llenado o siendo receptor en el vacío de todo cuando le rodea. Un ombligo subterráneo e intencionalmente visible. Y sobre todo ese gran vientre a punto de parir, recipiente muestra de la concepción de un ser distinto. La fertilidad encarnada en maternidad en Tlatilco permite ver el cuerpo femenino - y aún ahora- como sagrado y milagroso como la transfiguración de sangre en leche como alimento. Mirar a distancia estas figurillas femeninas, que parecen portar una máscara en sus rostros, permite reconcebir a la feminidad, poder observarla con nuevos ojos cíclicos, apreciar la belleza cadenciosa de lo femenino, sus posibilidades infinitas de colores, de adornos, de cabellos, de arreglos, de movimientos. E impulsa a mirar a la "mujer embarazada" como portadora de un gran secreto que sólo se revela a su tiempo, como sagrada, como madre dadora de vida en consonancia con la naturaleza y los ciclos de la vida.

Este retorno al elogio del cuerpo femenino, es la reflexión ante nuestro cuerpo que nos es tan primario, tan elemental, que ni siquiera podemos recordar si con él iniciamos la representación del mundo. Poseemos un cuerpo -en mi caso femenino- dialogante, el cual, se convierte en mi gente, en mis semejantes, en mis antepasados, en mis descendientes, y soy yo el ser temporal, mero eslabón de una herencia prolongada. Es mi centro de mediación con el mundo. Confluyen en él las formas y las leyes del universo. Se yergue como menciona López $^{28}$ como arquetipo 28 López, 22. 
y medida. Se proyecta al infinito y es punto de atracción de las proyecciones externas. En él brillan tanto las luces de los cielos como los fuegos subterráneos de los volcanes, y vibran en él, el animal, la planta, la piedra, el agua, el rayo. El cuerpo femenino es hoy día la articulación de las metáforas, es un puente prodigioso entre la realidad y el sueño, hace visible lo invisible ${ }^{29}$, y al estar embarazado incuba lo infinito en lo finito. En las partes más ocultas de este cuerpo femenino están la eterna experiencia cósmica y la recurrente inmediatez humana, aspecto que sin duda la sociedad tlatilca pudo plasmar en figuras femeninas de barro y que ahora a distancia podemos observar, contrarrestando la fugacidad del tiempo.

\section{Anexo}

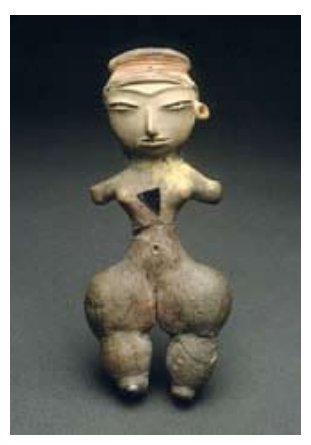

Imagen 1. Figurilla con espejo de pirita. Tlatilco, Estado de México. www.arteprehispanico.com.mx (Fecha de acceso: 24 de noviembre del 2007)

29 Arroyo, 12. 
Indexaciones: Repositorio de Revistas UCR, DIALNET, Latindex, REDALYC Directorio y recolector de recursos digitales del Ministerio de Cultura de España, Directory of Open Access Journals.

Diálogos Revista Electrónica de Historia ISSN 1409-469X. Número especial 2008. Dirección web: http://historia.fcs.ucr.ac.cr/dialogos.htm

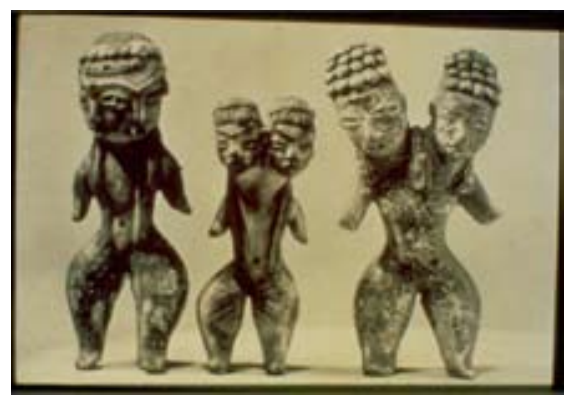

Imagen 2. Figurillas bicéfalas. Dualidad. Tlatilco, Estado de México.

www.homepage.smc.edu (Fecha de acceso: 14 de abril del 2008)

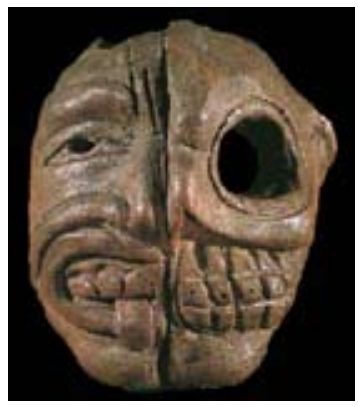

Imagen 3. Máscara dualidad. Tlatilco, Estado de México.

www.arqueomex.com (Fecha de acceso: 14 de abril del 2008)

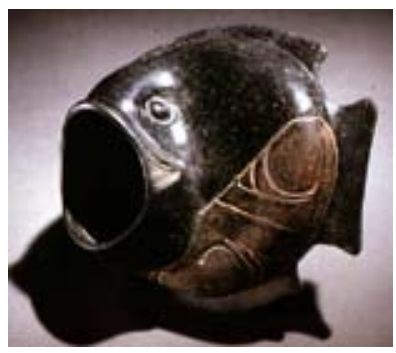

Imagen 4. Pez. Cultura lacustre. Tlatilco, Estado de México.

www.aal.ucsd.edu (Fecha de acceso: 4 de mayo del 2008) 
Indexaciones: Repositorio de Revistas UCR, DIALNET, Latindex, REDALYC Directorio y recolector de recursos digitales del Ministerio de Cultura de España, Directory of Open Access Journals. Diálogos Revista Electrónica de Historia ISSN 1409-469X. Número especial 2008. Dirección web: http://historia.fcs.ucr.ac.cr/dialogos.htm

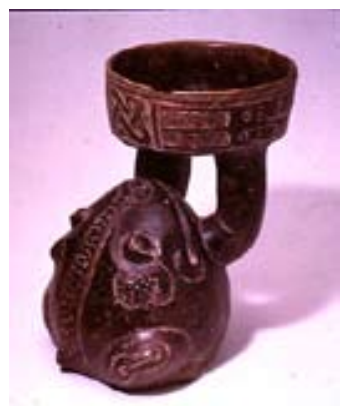

Imagen 5. Sapo y vasija. Depositario. Tlatilco, Estado de México.

www.art-and-archaeology.com (Fecha de acceso: 29 de abril del 2008)

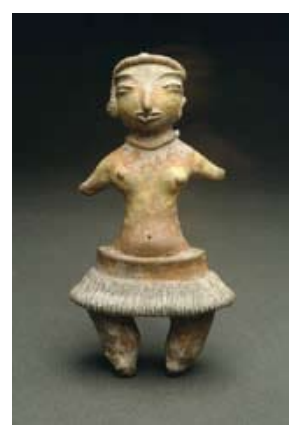

Imagen 6. Figurilla con faldellín y tocado que ciñe el pelo. Tlatilco, Estado de México. www. arteprehispanico.com.mx (Fecha de acceso: 24 de noviembre del 2007)

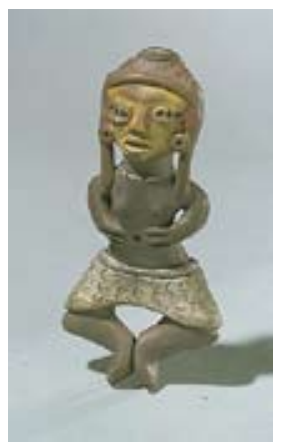

Imagen 7. Bailarina. Tlatilco, Estado de México. www.precolumbianantiques.ca (Fecha de acceso: 17 de abril del 2008) 


\section{O $19^{\circ}$ CONGRESO \\ D CENTROAMERICANO \\ DE HISTORIA \\ Universidad de costa Rica}

Indexaciones: Repositorio de Revistas UCR, DIALNET, Latindex, REDALYC Directorio y recolector de recursos digitales del Ministerio de Cultura de España, Directory of Open Access Journals. Diálogos Revista Electrónica de Historia ISSN 1409-469X. Número especial 2008. Dirección web: http://historia.fcs.ucr.ac.cr/dialogos.htm

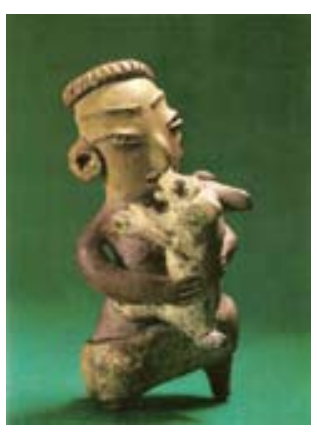

Imagen 8. Perro saltando a mujer hincada. Tlatilco, Estado de México. www.bellezachihuahuasusa.com

(Fecha de acceso: 17 de abril del 2008)

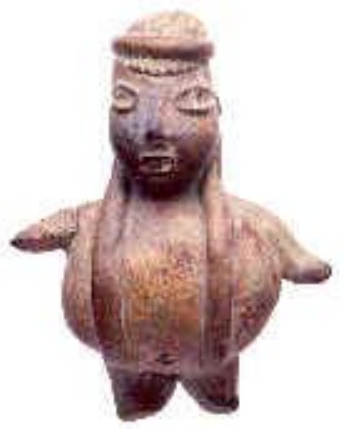

Imagen 9. Mujer embarazada. Tlatilco, Estado de México.

www.enkidumagazine.com (Fecha de acceso: 4 de noviembre del 2007) 